\title{
RANCANG BANGUN SISTEM INFORMASI AKUNTANSI PENJUALAN KREDIT PADA PD. LAJUAR MOTOR KARAWANG
}

\author{
Dede Nurrahman ${ }^{1}$, Asep $^{2}$, Faruq Aziz ${ }^{3}$ \\ ${ }^{1)}$ Sistem Informasi, Sekolah Tinggi Manajemen Informatika dan Komputer Nusa Mandiri \\ e-mail: dede.deh@nusamandiri.ac.id \\ ${ }^{2)}$ Sistem Informasi, Fakultas Teknik dan Infromatika, Universitas Bina Sarana Informatika \\ e-mail: asep.aep@bsi.ac.id \\ ${ }^{1)}$ Sistem Informasi Akuntansi, Fakultas Teknik dan Infromatika, Universitas Bina Sarana Informatika \\ e-mail: faruqaziz1997@gmail.com
}

\begin{abstract}
Abstrak
Penelitian ini bertujuan untuk merancang sistem informasi akuntansi penjualan kredit belum terkomputerisasi pada Lajuar Motor Karawang. Sehingga, menunjukkan bahwa perancangan Sistem Informasi Akuntansi Penjualan Kredit dapat memberikan dampak untuk menghindari terjadinya kesalahan. Yang digunakan pihak Perusahaan sebagai alat bantu perancangan dan pengelolaan dalam kegiatan penjualan kredit di Lajuar Motor Tunggakjati-Karawang. Metode yang digunakan adalah wawancara dan observasi , penelitian ini dilakukan pada Lajuar Motor Karawang yang terletak di jalan Proklamasi - Karawang. Hasil penelitian dari perancangan sistem informasi akuntansi penjualan kredit adalah memudahkan dalam melakukan pencatatan penjualan kredit yang akurat di bandingkan dengan sistem manual yang digunakan pada Lajuar Motor. Selama ini pihak perusahaan menggunakan sistem manual dalam pencatatan transaksi penjualan, padahal dengan menerapkan sistem informasi akuntansi penjualan, pihak perusahaan akan meminimaliskan resiko dalam kesalahan pencatatan dan transaksi penjualan, sehingga mendapatkan informasi yang lebih akurat dan lengkap. Hasil yang ingin dicapai adalah dapat membuat suatu sistem penjualan tunai terkomputerisasi untuk dapat membantu dalam menyelesaikan masalah-masalah yang terjadi di PD. Lajuar Motor Karawang. Kesimpulan sistem penjualan tunai terkomputerisasi dapat menyelesaikan masalah-masalah yang terjadi pada sistem pencatatan manual.
\end{abstract}

Kata kunci: Sistem Informasi Akuntansi, Sistem Penjualan Kredit, Akuntansi Penjualan

\begin{abstract}
The objective of this research is to stake out the computerized credit sales information system at the credit Sales Lajuar Motor Karawang. So, it shows that credit sales information system design can give good effect for avoiding fault. Its used for the shop owner as a tool to help that programing and management in activity of credit sales in credit Sales Lajuar Motor Karawang. The methods used are interview and documentation, this research has been done on the credit Sales Lajuar Motor Karawang at street Proklamasi - Karawang. The result from this program can make easier in doing record of cash sales compare to manual system which is used on the credit Sales Lajuar Motor Karawang. During this time, the factory owner uses the manual system in recording the credit sales transaction, although in applying computerized credit sales information system, credit Sales Lajuar Motor Karawang will minimize the risk in the faults record, note and sales transaction, so it can get the information which more accurate and complete. The results to be achieved are able to make a computerized cedit sales system to be able to assist in resolving the problems that occur in the credit Sales Lajuar Motor Karawang. In conclusion, computerized cash sales system can solve the problems that occur in manual recording system.
\end{abstract}

Keywords: Accounting Information System, Credit Sales System, Credit Sales Accounting 


\section{PENDAHULUAN}

Teknologi di masa sekarang ini berkembang dengan pesat ke dalam berbagai bidang, dengan teknologi sebuah informasi bermanfaat dapat cepat didapatkan bahkan dalam waktu yang singkat. Teknologi membuat sistem manual menjadi sistem yang dapat otomatis dengan akses yang mudah difahami. Semua bidang sangat disarankan untuk memanfaatkan teknologi informasi dalam menopang berbagai kegiatan, bahkan beberapa bidang memang sudah mengharuskan memanfaatkan teknologi. Teknologi yang ada, tentunya membuat perubahan pula pada sistem yang berlaku, penggunaan perangkat keras seperti komputer dan perangkat lunak seperti aplikasi penunjang informasi tentu sudah menjadi kebutuhan utama bagi bidang yang memang memanfaatkan teknologi informasi. Tidak terkecuali bidang perekonomian dari jasa hingga dagang tunai maupun kredit.

Penjualan berupa tunai maupun kredit menjadi salah satu aspek dalam bidang perekonomian yang memerlukan teknologi informasi baik sebagai strategi pemasaran saja maupun penjualan itu sendiri sebagai cara meningkatkan pasar yang efektif dan efisien. Berbagai bidang usaha dagang dalam penjualan khususnya kredit tentunya sangat terasa manfaat dari perkembangan teknologi informasi tersebut.

Namun pada kenyataannya masih ada perusahaan-perusahaan belum menggunakan sistem otomatis yang sebenarnya akan lebih tepat waktu dan tepat guna jika memanfaatkan teknologi yang ada. PD Lajuar Motor menjadi salah satu perusahaan yang bergerak dalam aspek penjualan kredit motor dan mobil yang belum terotomatisasi. Hal ini disebabkan karena masih kurangnya pengetahuan pegawai serta pimpinan mengenal hubungan manajemen perusahaannya dengan sistem komputer dalam pemanfaatan teknologi informasi. Selama menggunakan sistem manual menyebabkan seringkali terdapat data yang tidak akurat, rawan pemanipulasian data serta pencatatan yang kurang tepat guna dan tepat waktu.

Dengan menggunakan teknologi informasi, tentunya perusahaan dapat melakukan proses penyimpanan data dengan mudah dan cepat, karena tingkat kecepatan dan penyimpanan data pada komputer lebih aman dan rapi, sehingga mudah menemukan kembali data yang digunakan, data yang otomatis di simpan juga dapat meminimalisasi ketidak akuratan data serta pemanipulasian data dapat dicegah. untuk itu kami mencoba membahas ruang lingkup yang kecil dalam sistem penjualan kredit.

\section{METODE}

Metode pengembangan perangkat lunak yang digunakan yaitu metode Waterfall. Menurut Sukamto dan Shalahuddin (2016:28) menjelaskan bahwa "Model SDLC air terjun (waterfall) sering juga disebut model sekuensial linier (sequential linear) atau alur hidup klasik (classic life cycle)". Model air terjun menyediakan pendekatan alur hidup perangkat lunak secara sekuensial atau terurut dimulai dari analisis, desain, pengodean, pengujian, dan tahap pendukung (support).

1 Analisia kebutuhan perangkat lunak

Menganalisia semua kebutuhan termasuk dokumen dan antarmuka yang diperlukan guna menentukan solusi perangkat lunak yang akan digunakan sebagai proses komputerisasi sistem.

2 Desain

Mendefinisikan kebutuhan sistem yang terkait dengan pengembangan aplikasi terkait rancangan database, rancangan perangkat lunak dan antarmuka pengguna yang akan dibuat.

3 Bahasa Pemrograman

Menentukan bahasa pemrograman yang akan digunakan dan menentukan apakah program yang dibuat termasuk pemrograman terstruktur atau berbasis object.

4 Pengetesan

Mendeskripsikan proses pengujian yang akan dilakukan. 


\section{Dukungan}

Mendefinisikan upaya-upaya pengembangan terhadap sistem yang sedang dibuat dalam menghadapi mengantisipasi perkembangan maupun perubahan sistem bersangkutan terkait dengan perangkat keras dan perangkat lunak yang akan digunakan

\section{HASIL DAN PEMBAHASAN}

1. Tinjauan Perusahaan

PD Lajuar Motor adalah sebuah perusahaan dagang yang bergerak di bidang jual beli sepeda motor baik tunai maupun kredit.Perusahaan ini didirikan oleh bapak Taryan Setiawan pada tahun 2013 yang berlokasi di Jati Ilir 1RT02/08 kelurahan tunggak jati kecamatan karawang barat kabupaten karawang.bapak Taryan Setiawan pada tahun 2013 yang berlokasi di Jati Ilir 1RT02/08 kelurahan tunggak jati kecamatan karawang barat, karawang.

2. Permasalahan

Permasalahan yang ada pada sistem penjualan kredit PD Lajuar Motor Karawang menurut hasil analisa dari penulis, terlihat bahwa permasalahan yang dihadapi adalah pengolahan transaksi penjualan yang sangat lambat karena banyak perjanjian yang harus pelanggan buat dengan pihak showroom sehingga mengakibatkan ketidakpuasan pelanggan, tidak adanya rincian pembayaran oleh pelanggan pada surat pesanan, yang banyak berperan dalam semua bidang adalah bagian penjualan sehingga banyak data yang terlambat untuk di olah dan di laporkan kepada pemilik, sering terjadi keterlambatan dalam pengiriman pesanan pembelian.

3. Pemecahan masalah

Melihat gambaran umum permasalahan yang dihadapi oleh PD Lajuar Motor Karawang, penulis menyarankan bahwa perlu adanya rancang bangun sistem informasi yang dapat membantu mempercepat pengolahan data dan laporan penjualan khususnya bulanan, perlu adanya data pesanan pada surat pesanan untuk mempermudah pembeli mengetahui perincian biaya dan pembayaran angsuran, diperlukannya bagian gudang untuk membantu bagian penjualan sehingga tidak butuh waktu lama pesanan pembeli segera datang, memisahkan setiap laporan sehingga sistem untuk pembuatan laporan penjualan menjadi lebih terperinci

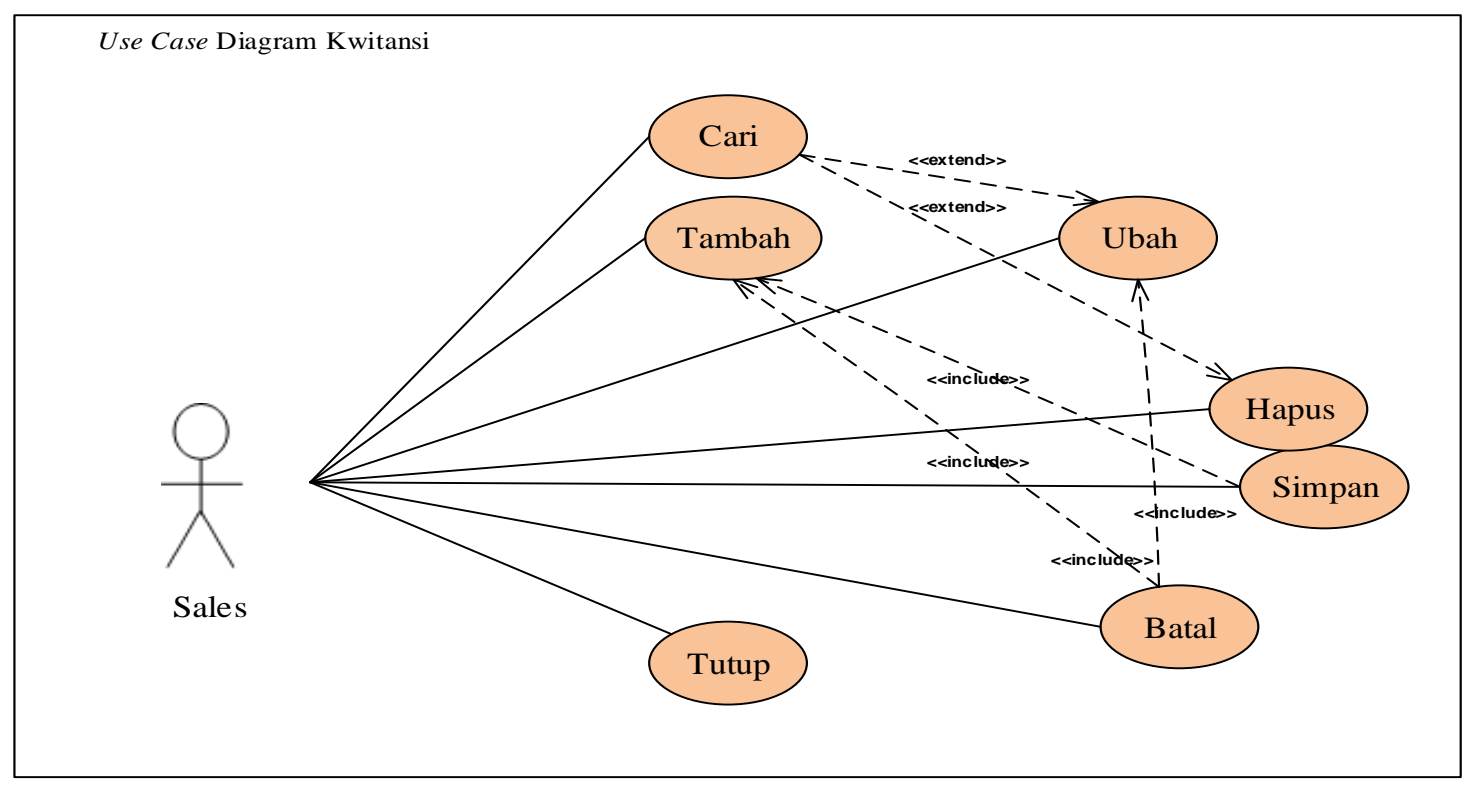

Gambar 1. Use Case Diagram Kwitansi 


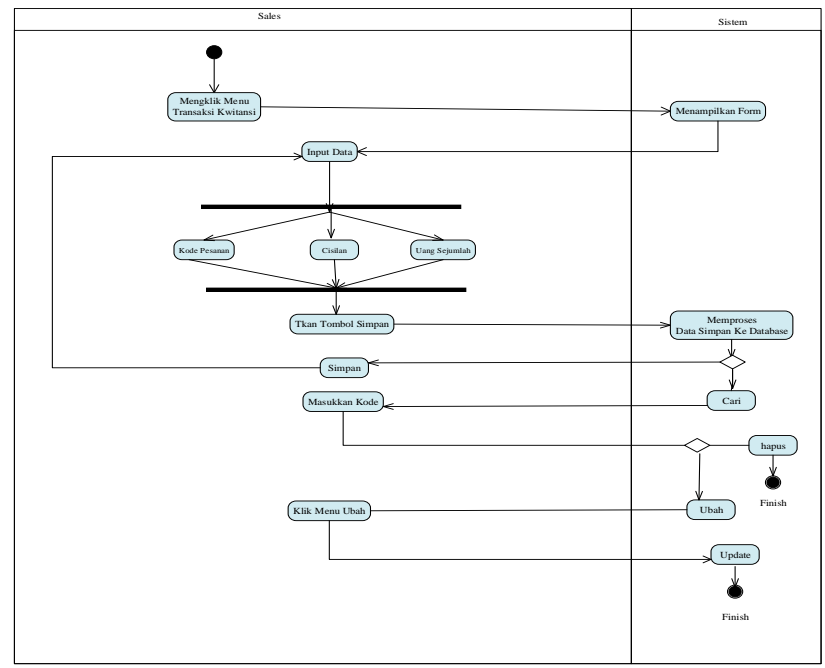

Gambar 2. Activity Diagram Kwitansi

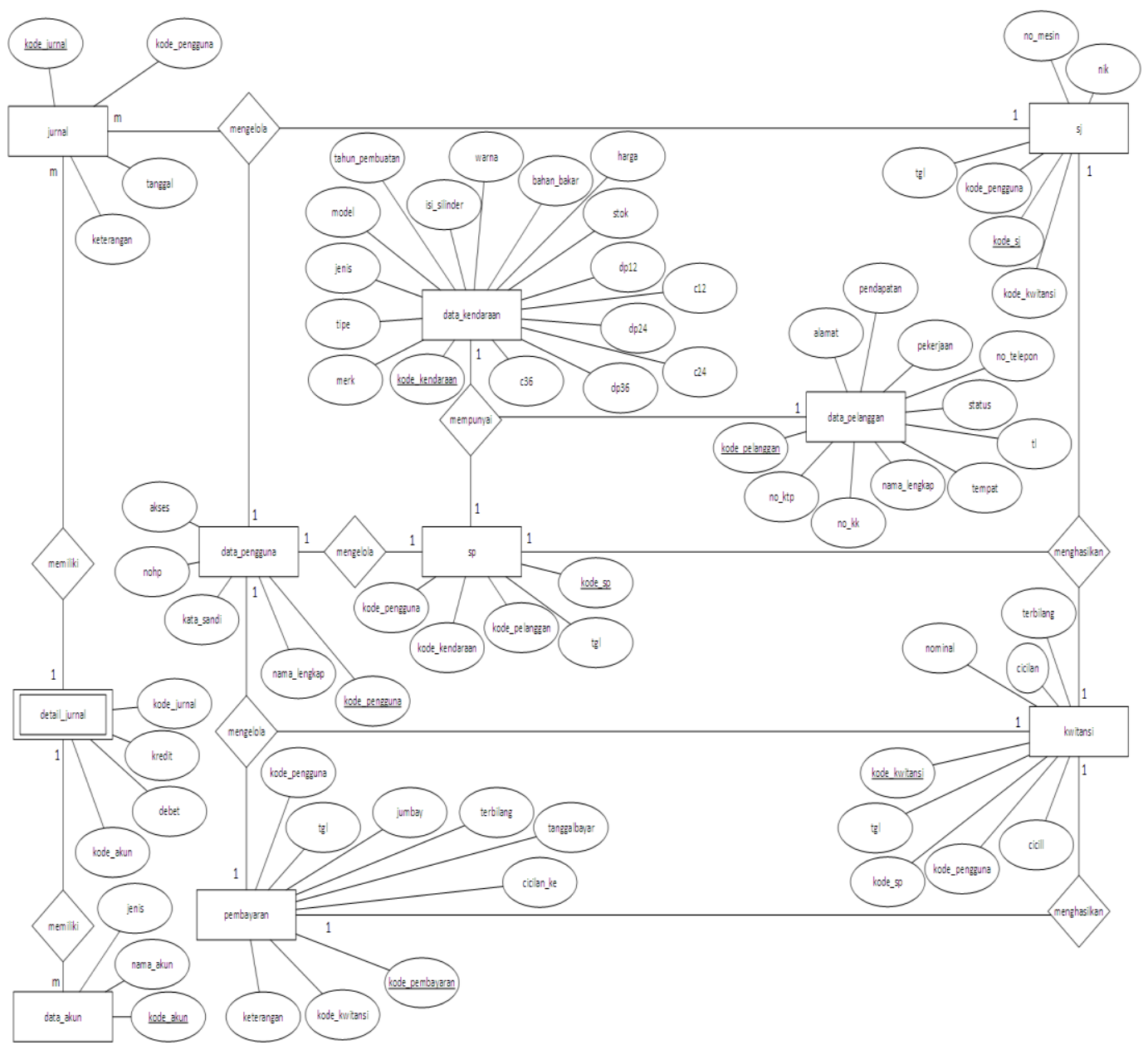

Gambar 3. Entity Relationship Diagram 


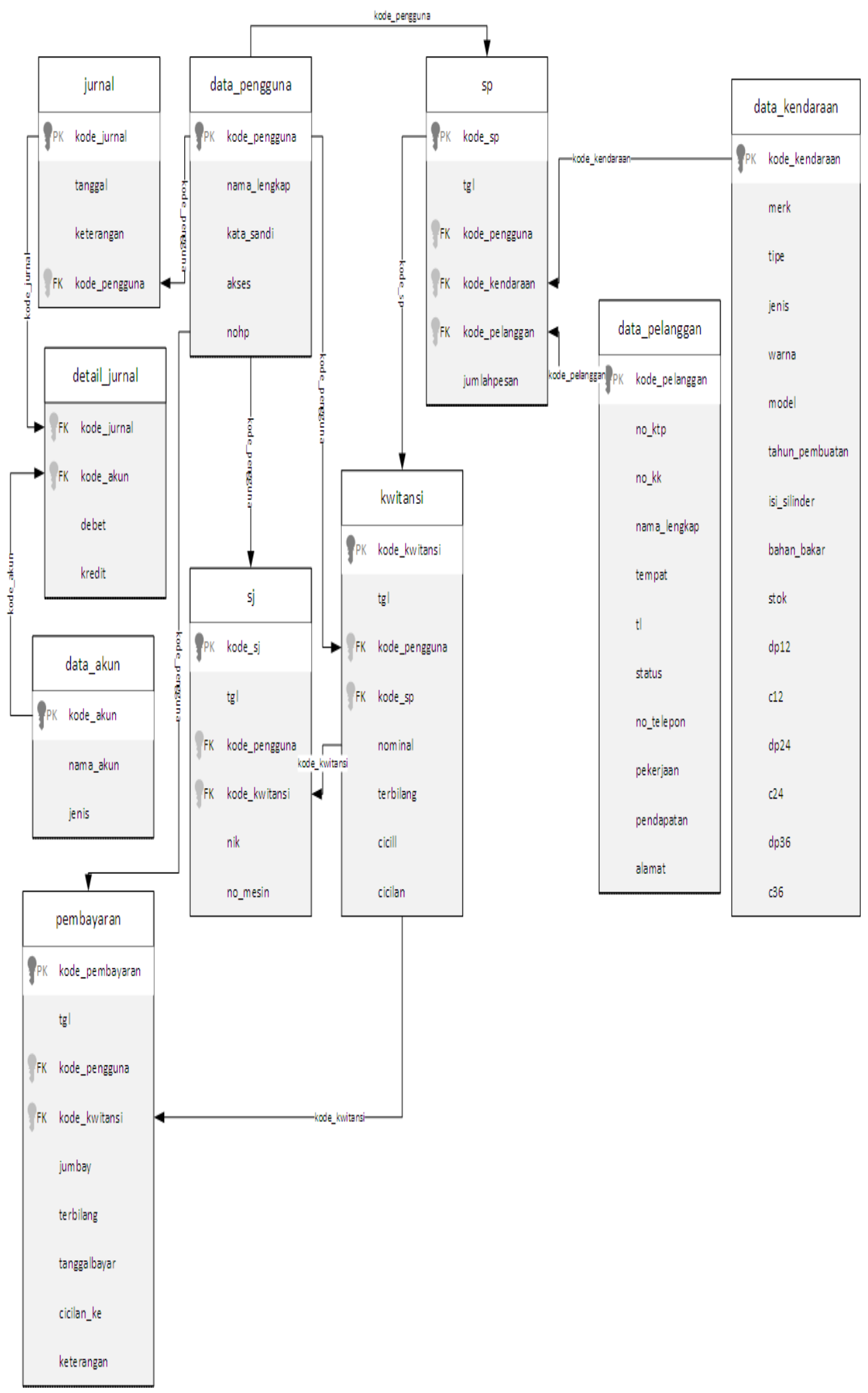

Gambar 4. Logical Record Structure 


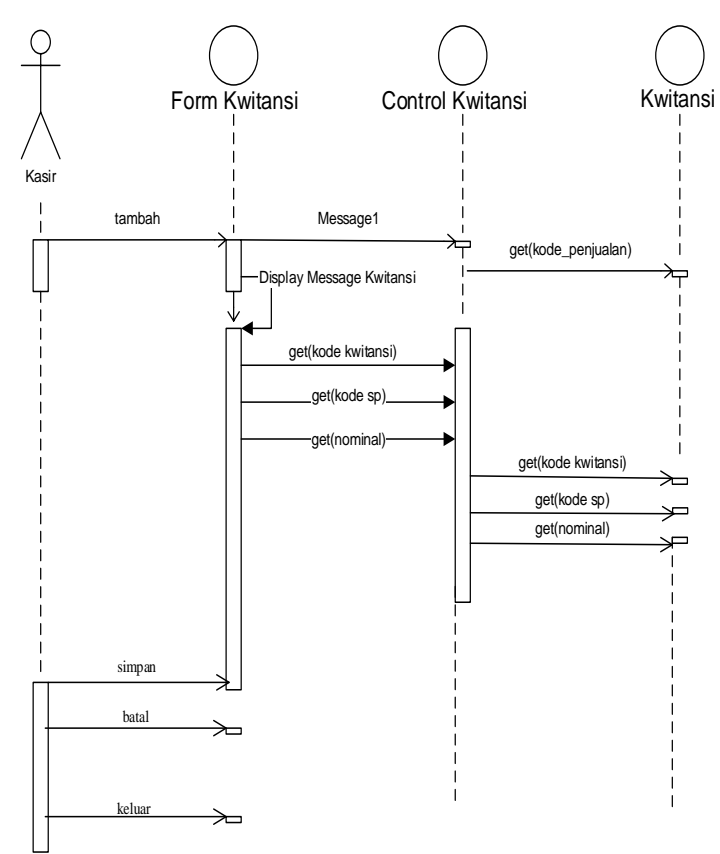

Gambar 5. Sequence Diagram

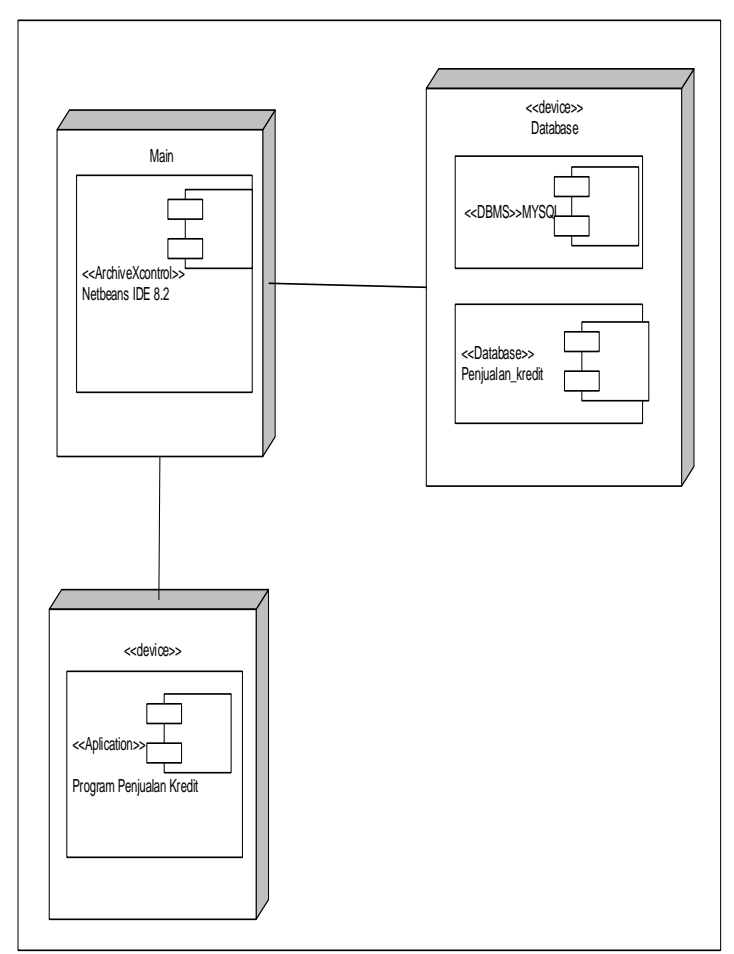

Gambar 6. Deployment Diagram

\section{SIMPULAN}

Dari pembahasan diatas dapat menyimpulkan bahwa dengan menggunakan sistem yang terkomputerisasi akan lebih mudah memperoleh data, laporan dan informasi yang dibutuhkan lebih cepat dan selain itu data yang telah tersimpan akan terjaga keamanannya dan terhindar dari kerusakan. 


\section{SARAN}

Berdasarkan kesimpulan diatas, maka penulis mencoba memberikan saran-saran dengan harapan dapat bermanfaat dan dapat menjalankan sistem penjualan kredit pada PD Lajuar Motor, Pada dasarnya sistem penjualan kredit pada PD Lajuar Motor sudah baik, namun dalam pencatatannya masih menggunakan cara manual yaitu Microsoft Excel, sehingga membutuhkan waktu yang lebih banyak agar dapat menyelesaikan pekerjaan tersebut dengan baik dan tepat. Komputerisasi sebagai alternatif dari permasalahan yang terjadi dan diharapkan dapat mengalami perubahan yang signifikan sehingga menghasilkan laporan yang dibutuhkan dengan tepat waktu dan tepat guna. Untuk lebih menunjang jalannya sistem yang baru, perlu diadakannya pelatihan untuk setiap bagian agar dapat mengerti sistem yang digunakan. Dan untuk perbaikan system yang telah dibuat sekarang mungkin kedepannya perlu ditambahkan system penjualan secara online, mengingat program yang sekarang dibuat masih program berbasis desktop dan diakses secara offline.

\section{UCAPAN TERIMA KASIH}

Penulis mengucapkan terimaksih kepada PD lajuar motor yang telah memberikan ruang kami untuk berkontribusi dalam menunjang usahanya.

\section{DAFTAR PUSTAKA}

Abdussomad. Akmaludin, Cep Adiwiharja. 2016. Sistem Informasi Akademik Berbasis Web pada SMK PGRI 2 Karawang. Vol.V NO.2, Agustus 2016. Diambil dari: http://ejournalab.com/index.php/jsi/article/view/95/pdf. (14 Juli 2018)

Rusmayanti, Atik. Sistem Informasi Pengelolaan Keuangan Pada Desa Ngadirejan. Vol.6 No 2.2014. Diambil dari: http://ijns.org/journal/index.php/speed/article/view/1321/1309. (08 Juni 2018)

Sukamto dan M. Shalahuddin. 2014. Rekayasa Perangkat Lunak Terstruktur dan Berorientasi Objek. Bandung Informatika.

TMBooks. 2017. Sistem Informasi Akuntansi: Esensi dan Aplikasi/TMBooks. Yogyakarta: ANDI 